\title{
Mégalithes de Normandie
}

Nicolas Fromont

\section{OpenEdition}

Journals

Édition électronique

URL : http://journals.openedition.org/rao/2214

DOI : 10.4000/rao.2214

ISBN : 978-2-7535-3432-2

ISSN : 1775-3732

Éditeur

Presses universitaires de Rennes

Édition imprimée

Date de publication : 25 décembre 2013

Pagination : 309

ISBN : 978-2-7535-3430-8

ISSN : 0767-709X

\section{Référence électronique}

Nicolas Fromont, "Mégalithes de Normandie », Revue archéologique de l'Ouest [En ligne], 30 | 2013, mis en ligne le 25 décembre 2013, consulté le 03 décembre 2020. URL : http://journals.openedition.org/ rao/2214; DOI : https://doi.org/10.4000/rao.2214

Ce document a été généré automatiquement le 3 décembre 2020.

Tous droits réservés 


\title{
Mégalithes de Normandie
}

\author{
Nicolas Fromont
}

\section{RÉFÉRENCE}

Rouch J., 2012 - Mégalithes de Normandie. Pierres de légendes, OREP Éditions, 114 p. (ISBN

978-2-8151-0028-1, 25,50€)

1 Avec cet ouvrage publié aux éditions OREP, J. Rouch renoue avec une longue tradition de publication d'inventaires des mégalithes de Normandie. Cependant, l'auteur ne propose pas ici un inventaire exhaustif, mais une sélection de monuments sur la simple base de ses promenades et intéressements aux légendes populaires. Néanmoins, le nombre et la variété des monuments présentés - dolmens, menhirs et polissoirs reflètent plutôt bien le polymorphisme du phénomène mégalithique normand. L'auteur évoque aussi des curiosités géologiques naturelles, appuyant ainsi sur les fantasmes qu'elles ont fait naître à travers les âges récents et sans doute aussi au Néolithique. On peut alors s'interroger sur les procédures de déclassement de la liste des Monuments historiques qui touchent certaines de ces curiosités.

2 L'ouvrage - fait rarement réalisé auparavant - traite des cinq départements normands. D'abord, un bref avant-propos rappelle le caractère non exhaustif de cet inventaire et la nécessité de préserver ce patrimoine. Puis, une introduction succincte replace le phénomène mégalithique dans le temps, évoque les cultes païens rendus à ces pierres et le combat du clergé, durant le Moyen Âge, pour en venir à bout. L'auteur y présente aussi différents types de monuments à partir des acquis de l'archéologie et, surtout, des traditions orales populaires ayant trait à l'origine ou aux soi-disant propriétés de ces pierres. Cette pseudo-classification, hétéroclite, colle bien avec le sous-titre de l'ouvrage, « Pierres de légendes ». Ensuite, les monuments retenus sont détaillés par département, puis par canton. Chacun fait l'objet d'une notice plus ou moins développée donnant la localisation du site, la nature des roches employées, leurs dimensions et, quand il y a lieu, les résultats de fouilles ou de découvertes fortuites. On pourra regretter que ne soit pas faite une plus large place aux résultats des 
explorations archéologiques récentes, mais il faut rappeler que l'auteur n'est pas archéologue. Enfin, quand il en a connaissance, l'auteur mentionne les légendes ou les anecdotes ayant trait aux monuments évoqués. On notera au moins une erreur concernant le site d'Ernes, dans le Calvados: les résultats de fouille relatés ne concernent pas la "Butte du Hue » en elle-même, mais l'un des sept monuments explorés à proximité immédiate par J.-L. Dron et G. San Juan, plus précisément le dolmen à couloir de « Derrière les Près ».

3 L'ouvrage est abondamment illustré par des photographies en couleur, des cartes postales - plus de 140 vignettes au total - et par plus d'une vingtaine de dessins en sépia qui reprennent le thème des légendes racontées. Sa mise en page est agréable, claire et aérée. Un index des communes, placé en fin d'ouvrage, et cinq cartes de répartition des monuments (une par département visité) facilitent la recherche d'informations dans cet ouvrage de 114 pages.

4 Le chercheur éclairé ne trouvera pas d'informations scientifiques dans ce livre ; ce n'est d'ailleurs pas son but. Il doit plutôt se découvrir comme un guide de loisirs et constitue en cela une agréable invitation à la découverte ou à la redécouverte de monuments souvent perdus dans la campagne. On terminera en remerciant J. Rouch de l'intérêt qu'elle porte à ce patrimoine, à tel point que sa curiosité l'a conduite à découvrir un dolmen totalement inédit. Cet intérêt est une des clés de la préservation de ces vestiges souvent discret, dispersés et fragiles.

\section{AUTEURS}

\section{NICOLAS FROMONT}

Inrap Grand-Ouest 